\title{
In-Depth Review of Human Immunodeficiency Virus-Associated Nephropathy
}

\author{
${ }^{1}$ Nitipong Permpalung, ${ }^{2}$ Wikrom Chaiwatcharayut, ${ }^{3}$ Sira Korpaisarn, \\ ${ }^{1}$ Wisit Cheungpasitporn, ${ }^{1}$ Daych Chongnarungsin and ${ }^{1}$ Edward F. Bischof

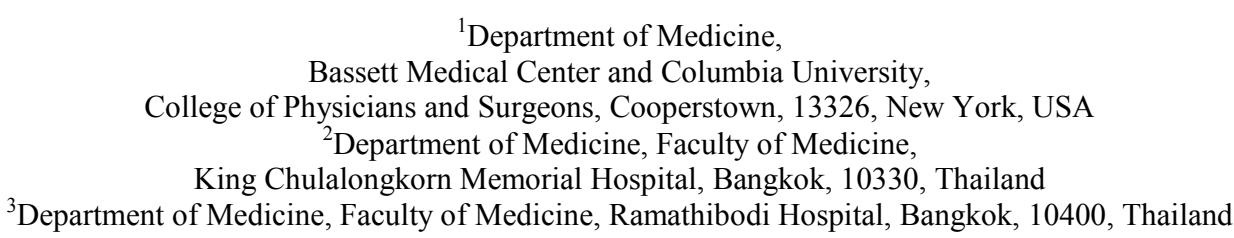

Received 2013-03-19, Revised 2013-03-25; Accepted 2013-04-19

\begin{abstract}
Human Immunodeficiency Virus (HIV)-Associated Nephropathy (HIVAN) is one of the most important renal complications found in HIV-infected individuals. Morbidity and mortality in this group of patients increases due to End-Stage Renal Disease (ESRD). Classic histological characteristics of HIVAN are collapsing Focal Segmental Glomerulosclerosis (FSGS), microcystic tubular dilation and interstitial inflammation and fibrosis. High prevalence of HIVAN among people of African descent can be explained by host genetic susceptibility, which is associated with several genes on human chromosome 22. HIV can infect renal epithelial cells via unconventional mechanisms and cause changes in multiple host cellular pathways, especially in renal tubular cells and podocytes. Accurate diagnosis of HIVAN relies mainly on renal biopsy. Antiretroviral therapy is the mainstay treatment for HIVAN and current standard guidelines recommend the initiation of Highly Active Antiretroviral Therapy (HAART) in all HIV-infected individuals with HIVAN, regardless of CD4 level. Other possible treatments for HIVAN including steroids, Angiotensin Converting Enzyme (ACE) inhibitors, renal replacement therapy and renal transplantation are reviewed in this chapter.
\end{abstract}

Keywords: Human Immunodeficiency Virus, Glomerulosclerosis, Transplantation, End-Stage Renal Disease, Associated Nephropathy

\section{INTRODUCTION}

Human Immunodeficiency Virus (HIV)-associated nephropathy or HIVAN was first described in patients with Acquired Immunodeficiency Syndrome (AIDS) in (Pardo et al., 1984; Rao et al., 1984). Originally, it was named AIDS-nephropathy; however, because renal histopathologic defective findings were demonstrated in asymptomatic patients, the name was changed to HIVAN. Collapsing Focal Segmental Glomerulosclerosis (FSGS) with tubulointerstitial lesions, the classical histopathologic pattern in HIVAN is more prevalent in patients of African descent (Lucas et al., 2004; Lescure et al., 2012; Schwartz et al., 2005). At present, medical laboratories and clinical societies have focused on host genetic factors and complex host-viral genetic interactions to understand the pathogenesis of this disease among various populations and to develop potentially effective therapy.

\subsection{Pathogenesis}

\subsubsection{Host Genetic Susceptibility}

Human genetic factors are important to determine an individual's degree of susceptibility to the development Corresponding Author: Nitipong Permpalung, Department of Medicine, Bassett Medical Center and Columbia University, College of Physicians and Surgeons, Cooperstown, 13326, New York, USA 
of HIVAN from HIV infection. Data from the United States Renal Data System (USRDS) shows that almost $90 \%$ of patients with End-Stage Renal Disease (ESRD) from HIVAN are African-American (USRDS, 2010).

Studies in animal models have improved our understanding of the pathogenesis of HIVAN. Among all animal models, the HIV-transgenic mouse model, which expresses HIV genes on their murine genetic background ("transgenic 26" or "Tg26"), is the most studied one. Based on the existence of different renal phenotypes depending on the mice's genetic background, "HIVAN1" and "HIVAN2", the two susceptibility loci associated with HIVAN in Tg26 mice were identified (Gharavi et al., 2004; Chan et al., 2009).

HIVAN1 is on murine chromosome 3. This locus strongly associates with renal disease in mice (Gharavi et al., 2004). It correlates with human chromosome 3q25-27, which was previously linked to diabetic nephropathy (Imperatore et al., 1998; Moczulski et al., 1998) and hypertensive nephropathy (DeWan et al., 2001). HIVAN1 also increases susceptibility to the development of HIVAN (Chan et al., 2009).

HIVAN2 is on murine chromosome 13. Together with HIVAN1, both loci are involved in the transregulation of podocyte genes including Nephrosis 2 homolog (Nphs2) gene which encodes podocin, a protein component in the slit diaphragm of podocytes (Papeta et al., 2009). This finding adds to the evidence that podocyte genes are regulated by a network of other genes. In the presence of host susceptibility alleles, this network can be altered by HIV infection (Medapalli et al., 2011).

In human, several loci associated with HIVAN were identified. Myosin Heavy chain-9 (MYH9) and Apolipoprotein L1 (APOL1) are the two most important loci studied.

MYH9 is on human chromosome 22. It is expressed in podocytes and encodes non-muscle myosin heavy chain IIA. Despite being proven to be associated with many renal diseases (e.g., hypertensive ESRD (Kao et al., 2008), idiopathic FSGS and HIVassociated FSGS in HIVAN (Kopp et al., 2008)), the role of MYH9 in the pathogenesis of HIVAN still remains unclear.

APOL1 is also on human chromosome 22. This gene was identified later than MYH9; however, it has been proven to possess a stronger association with HIVAN. This apolipoprotein L1-encoding gene was found to be present only among African participants in the 1,000 Genome Project. Its product has an ability to lyse Trypanosome brucei brucei, an African parasite.
Therefore, the high prevalence of APOL1 in people of African descent was hypothesized to be a result of positive selection, in which people with APOL1 gene tend to live longer (the same way that individuals with sickle-cell heterozygotes have a selective advantage in malaria-endemic regions) (Freedman et al., 2009). To date, two alleles in the APOL1 locus, named G1 and G2, have been identified as risk alleles. These risk alleles follow an autosomal recessive pattern of inheritance and are in strong linkage disequilibrium with the most important MYH9 risk haplotype. Thus, the association between MYH9 and renal disease may be explained by the presence of APOL1 risk allele which is linked with that MYH9 risk haplotype (Freedman et al., 2009).

\subsection{Role of HIV}

The introduction of combined Antiretroviral Therapy (cART) thus helps decrease its incidence, resulting in a plateau in the incidence of ESRD from HIVAN in the United States (USRDS, 2010; Wyatt et al., 2008).

The role of HIV in the pathogenesis of HIVAN was initially studied in HIV-transgenic mice. Reciprocal transplantation studies between $\mathrm{Tg} 26$ and wild-type mouse focusing on podocyte-specific expression of HIV genes showed that viral gene expression within the kidney itself played an important pathologic role in the development of HIVAN (Rosenstiel et al., 2009a; Bruggeman et al., 1997). Subsequent studies confirmed that HIV has an ability to infect renal epithelial cells (Marras et al., 2002) and HIV nucleic acid was found in podocytes, parietal epithelial cells, tubular epithelial cells, T-cells and macrophages in human HIVAN renal biopsies (Bruggeman et al., 2000; Tanji et al., 2006).

Phylogenetic comparative analysis of HIV nucleic acid sequences derived from renal epithelial cells and peripheral blood mononuclear cells showed a divergent pattern, suggesting that the kidney probably acts as a separated compartment where kidney-specific viral evolution takes place (Marras et al., 2002). Some pieces of evidence even suggested the existence of renal tropic strains of HIV (Ray et al., 1998). HIV has been proven to be able to replicate in the kidney even though the patients had achieved serological viral suppression from the combination antiretroviral therapy (Medapalli et al., 2011).

How can HIV infect kidneys? Since renal epithelial cells possess no traditional HIV surface receptors (CD4) or co-receptors (CXCR4 or CCR5) (Marras et al., 2002; Eitner et al., 2000), other pathways must be used by the virus to enter those cells. Several mechanisms for cell-free 
HIV infection of tubular epithelial cells (Hatsukari et al., 2007) and podocytes (Mikulak and Singhal, 2010; Mikulak et al., 2010) have been proposed. In one study, tubular epithelial cells were co-cultured with infected Tcells. The result showed efficient viral nucleic acid transfer which required direct cell-cell contact and cell surface heparin sulfate proteoglycans (which helped HIV to attach on macrophages and dendritic cells), but did not depend on an interaction with CD4 (Chen et al., 2011). Comparing the cell to cell contact mechanism and cellfree mechanism (exposure of tubular epithelial cells to a large amount of cell-free virus), the former mechanism resulted in a greater number of transferred viral nucleic acids. Moreover, de novo viral protein synthesis following this cell-cell contact could not be blocked by reverse transcriptase, protease or integrate inhibitors (Chen et al., 2011). Theoretically, HIV infection of renal epithelial cells may occur via direct cell-cell contact with lymphocytes infiltrating the renal parenchyma (Wyatt et al., 2012).

Of all HIV genes that were studied, nef, vpr and tat are three HIV genes that have potential roles in the development of pathology in HIVAN.

Nef is important in the development of glomerular lesion in HIVAN. It is involved in de-differentiation and proliferation of podocytes, which normally are terminally differentiated (Husain et al., 2002; 2005; He et al., 2004; Zhong et al., 2005; Zuo et al., 2006).

$\mathrm{Vpr}$ plays a role in the development of tubular lesion in HIVAN. Its expression in tubular epithelial cells is associated with G2 cell cycle arrest, impaired cytokinesis and finally apoptosis (Zhong et al., 2005; Rosenstiel et al., 2008; 2009b; Snyder et al., 2010; Vashistha et al., 2008). A synergistic effect of nef and vpr was observed in a study which showed that mice with both nef and vpr expression developed more severe nephropathy (Zuo et al., 2006).

That may have a role in podocyte de-differentiation (Doublier et al., 2007), however, its role is unclear since mice with podocyte-specific expression of that did not develop pathology. It might be possible that circulating tat released from HIV infected cells may have an effect on podocytes in vivo (Zuo et al., 2006).

\subsection{Host Response to HIV Infection}

HIV infection causes multiple changes in host cellular pathways, resulting in pathological changes observed in HIVAN. Those histological characteristics of HIVAN are collapsing form of FSGS, microcystic tubular dilation and interstitial inflammation and fibrosis (Medapalli et al., 2011).
Tubular epithelial cells infected with HIV have changes including up-regulation of cellular pathways mainly involved in cell cycle arrest and apoptosis. HIV vpr gene induces an up-regulation of FAT10 (ubiquitinlike protein), resulting in apoptosis of tubular epithelial cells and finally the tubular dilation and atrophy characteristic of HIVAN (Vashistha et al., 2008; Kapasi et al., 2002; Ross et al., 2005; 2006a; 2006b). Furthermore, HIV infection of tubular epithelial cells also induces expression of multiple inflammatory mediators which may contribute to the prominent tubulointerstitial inflammation feature of HIVAN (Ross et al., 2006b). This justifies potential benefit from corticosteroid in the treatment of HIVAN (Yahaya et al., 2013).

Podocytes infected with HIV also have changes in cellular pathways. They have decreased expression of typical markers (such as synaptopodin and Wilm's tumor-1) and Cyclin-Dependent Kinase (CDK) inhibitors (p27, p67); the latter indicates that they re-enter the cell cycle. On the other hand, they have increased expression of desmin (intermediate filament protein) and some proliferation markers such as Ki-67 and cyclins (A, D1) (Barisoni and Kopp, 2002; Barisoni et al., 1999; 2000; Schwartz et al., 2001).

HIV also induces MAPK 1,2 activation and Stat-3 pathway in podocytes. These pathways are induced mainly by HIV nef gene and correlate with podocyte proliferation seen in vitro studies (He et al., 2007). AllTrans Retinoic Acid (ATRA) was shown to suppress HIV-induced activation of these pathways in cultured podocytes (He et al., 2007).

Homophilic adhesion molecule sidekick-1 (sdk-1) is a mediator of cellular adhesion that is up-regulated in HIV infected podocytes (Kaufman et al., 2004) and is proven to have a crucial role in the development of FSGS (podocyte clustering in classical pseudo crescent formation) (Kaufman et al., 2007; 2010).

More recently, a mammalian Target of Rapamycin (mTOR) pathway was also found to be up-regulated in HIV-transgenic mice (Kumar et al., 2010).

Several possible therapeutic agents targeting at each host pathway in the pathogenesis of HIVAN are being investigated. This includes CDK inhibitor, Stat-3 inhibitor, ATRA, mTOR inhibitor sirolimus, corticosteroid, ACEI and ARB (Wyatt et al., 2012).

\subsection{Diagnosis}

HIVAN is characterized by the presence of heavy proteinuria and collapsing focal segmental glomerulonephritis with microcystic tubular dilatation in renal pathology (Ray, 2012). Data from many 
retrospective studies showed that almost $40 \%$ of biopsy-proven renal diseases in HIV patients with clinical backgrounds of massive proteinuria and progressively worsening renal function were not HIVAN (Schwartz et al., 2005; Atta et al., 2006; Wearne et al., 2012); therefore, histopathologic diagnosis is crucial for definitive diagnosis. Considering new taxonomy for podocytopathies, HIV1 could induce at least three different podocytopathies including focal segmental glomerulonephritis, collapsing glomerulopathy and diffuse mesangial sclerosis (D’Agati et al., 2004; Barisoni et al., 2007).

\subsection{Treatment}

Several therapeutic strategies have been proposed to treat HIV-infected patients with HIV-Associated Nephropathy (HIVAN). Treatment modalities include steroid, Angiotensin Converting Enzyme (ACE) inhibitors and antiretroviral medications could slow down the progression of HIVAN to ESRD or improve renal survival time. However, the major drawback of the evidence is that there are currently no randomized clinical control trials to demonstrate effective treatment of HIVAN.

\subsection{Antiretroviral Therapy}

The introduction of HAART in 1995-1996 was associated with dramatically decreased in mortality rates from AIDS and End Stage Renal Disease (ESRD) in HIV-infected patients. This information suggests a possible beneficial role of antiretroviral drugs in HIVAN. The first 12-year observational cohort study (1989-2001) showed the 50\% decreased incidence of HIVAN in 1998-2001 compared to 1995-1997 which was associated with increased HAART use (Lucas et al., 2004). This conclusion has been supported by another 12-year retrospective study (1995-2007) of biopsyproven glomerular disease in HIV population (total 88 renal biopsies), which showed decreased prevalence of HIVAN compared to classic FSGS in 2004-2007 which had the highest proportion of HAART-treated patients (Lescure et al., 2012).

In addition, there are a few studies demonstrating the effect of HAART and renal survival time. Schwartz et al. (2005; 2001) demonstrated mathematical model to calculate the effect of HAART and ESRD using data from Centers of Disease Control and Prevention (CDC) and USRDS which suggested HAART could slow the progression of ESRD in HIV-infected individuals by $38 \%$ (Schwartz et al., 2005). Atta et al. (2006) found that ARV-treated patients, either with monotherapy, combination ART or HAART regimens, had significantly higher renal survival time than patients who did not receive treatment. Subgroup analysis trended towards better renal survival in patients with complete virologic response (Atta et al., 2006). The largest renal biopsy series (221 renal biopsies in HIV-positive patients) in South Africa emphasized most untreated HIV-related renal diseases patients with combined antiretroviral therapy died of renal failure (Wearne et al., 2012). Interestingly, the benefit of HAART on HIVAN was contradicted by one retrospective study (total 61 HIVAN with 45 biopsy-confirmed). The study demonstrated that once severe HIVAN was diagnosed, HAART and HIV viral suppression could not prevent progression towards ESRD (Post et al., 2008).

Considering the data from observational, prospective multicenter cohort studies and retrospective studies; 2012 US Department of Health and Human Services (DHHS) and International AIDS Society treatment guidelines recommended starting Highly Active Antiretroviral Therapy (HAART) in HIV-infected individuals with HIV-associated nephropathy regardless of CD4 level (Thompson et al., 2012; PAGAA, 2003).

\subsection{Renin-Angiotensin-Aldosterone System Inhibitors}

The possible efficacy of ACEI was proposed for the first time in a case report. Burns et al. (1994) reported that fosinopril had a positive effect in decreasing proteinuria in biopsy-proven HIVAN (Burns et al., 1994). Two years later, Burns et al. (1997) conducted a non-randomized prospective cohort study to demonstrate the efficacy of fosinopril in 20 biopsy-proven HIVAN (11 presented with non-nephrotic-range proteinuria and 9 presented with nephrotic-range proteinuria). The preliminary report showed that fosinopril may stabilize serum creatinine and decrease proteinuria up to 24 weeks in patients with non-nephrotic range proteinuria, but only 12 weeks in nephrotic range patients (Burns et al., 1997). In the same year, the effect of captopril was shown to improve renal survival time in 18 biopsy-proven HIVAN, compared to controls matched for age, gender, race and baseline serum creatinine. The median length of survival was 83 and 30 days in treated group and untreated group, respectively (Kimmel et al., 1996). Another 5-year nonrandomized prospective cohort study supported the concept of fosinopril-improved renal survival time in both non-nephrotic range and nephrotic range groups. Total 44 treated and controlled patients 
were matched for age, baseline median CD 4 count, serum creatinine level, proteinuria; however, fosinopriltreated groups had higher rate of HAART exposure. The median survival time was 146.5 and 479.5 days in untreated groups and treated groups, respectively (Wei et al., 2003). It is unclear if there is a class effect from other ACEIs for treatment in HIVAN as recent clinical studies we have reviewed only demonstrated potential benefits in fosinopril and captopril (Burns et al., 1997; Kimmel et al., 1996; Wei et al., 2003).

In brief, even though the available data regarding the efficacy of fosinopril in decreasing proteinuria and improving renal survival time came from a group of researchers and might have had bias due to lack of randomization, given fosinopril with HAART in selected patients without hyperkalemia, hypotension or other contraindications for ACEI may provide benefits more than risks.

\subsection{Corticosteroids}

Most of the available information for corticosteroids in HIVAN was published in pre-HAART era. Most of evidence came from case reports or small cohort study without controlled groups and the majority of population in every study were already treated with ARVs or had a history of prior ARV exposure which could affect outcomes (Smith et al., 1994; Watterson et al., 1997). Smith et al. (1994) prospectively evaluated the effect of prednisone in 20 HIVAN patients and concluded that prednisone was able to improve serum creatinine and proteinuria. Duration of treatment varied for each patient (range 2 to 26); it was based on the response of serum creatinine, development of steroid-induced side effects or opportunistic infections. However, 19 patients in this study had exposed to at least ARV monotherapy (Smith et al., 1996). Another retrospective study in 21 biopsy-proven HIVAN, treated and controlled groups had non-significant baseline characteristics in term of comorbidities, renal functions, CD4 level, HIV viral load and potential co-founding medications use including ARVs and ACEI, demonstrated preserved renal function and no difference in the incidence of infection or hospitalization in treatment (Eustace et al., 2000).

\subsection{Renal Replacement Therapy and Renal Transplantation}

Though AIDS-defining illnesses have decreased after the introduction of antiretroviral drugs and HIV-infected individuals have longer life expectancy, late-stage organ diseases including End Stage Renal Disease (ESRD) have increased (Mocroft et al., 2002). Currently, renal transplantation and renal replacement therapy (hem dialysis and peritoneal dialysis) are valid options in selected patients. Renal transplantation was absolute contraindication in the past, due to a concern of drugdrug interactions of immunosuppressive drugs and ARVs and risks of Opportunistic Infections (OIs) in the setting of post-transplant immunosuppression.

Criteria for including HIV-infected patients on the transplant list (Trullas et al., 2011):

- Clinical criteria: Ideally, patients should not have OIs or AIDS-defining diseases. However, some OIs (previous tuberculosis, Pneumocystis jiroveci pneumonia, esophageal candidiasis) are not exclusion criteria in United States.

- Immunological criteria: CD4 should be more than 200 cells $/ \mathrm{mm}^{3}$

- Virological criteria: Patients should have undetectable HIV-1 RNA viral load.

- Other criteria: Patient should have favorable psychiatric evaluation and not actively use alcohol or substance.

\section{CONCLUSION}

HIVAN is an aggressive form of FSGS in HIVinfected patients, particularly in African-American population. Apart from HIV, host genetic susceptibility and host response to HIV infection also play a crucial role in the development of the disease. Only renal biopsy is definitive for diagnosis because no clinical criteria could provide accurate diagnosis of HIVAN. The information about treatment is still inconclusive; however, all standard treatment guidelines recommend initiating HAART in every HIV-infected individual with HIVAN, regardless of CD4 count. Other adjunctive therapy including ACEI might be considered in selected patients.

\section{REFERENCES}

Atta, M.G., J.E Gallant, M.H. Rahman, P.J. Scheel and D.M. Fine et al., 2006. Antiretroviral therapy in the treatment of HIV-associated nephropathy. Nephrol. Dial. Transplant, 21: 2809-2813. DOI: $10.1093 / \mathrm{ndt} / \mathrm{gfl} 337$

Barisoni, L. and J.B. Kopp, 2002. Modulation of podocyte phenotype in collapsing glomerulopathies. Microsc. Res. Tech., 57: 254-262. DOI: 10.1002/jemt. 10084 
Barisoni, L., H.W. Schnaper and J.B. Kopp, 2007. A proposed taxonomy for the podocytopathies: A reassessment of the primary nephrotic diseases. Clin. J. Am. Soc. Nephrol., 2: 529-542. DOI: 10.2215/CJN.04121206

Barisoni, L., L.A. Bruggeman, P. Mundel, P.E. Klotman and V.D. D'Agati, 2000. HIV-1 induces renal epithelial dedifferentiation in a transgenic model of HIV-associated nephropathy. Kidney Int., 58: 173181. DOI: 10.1046/j.1523-1755.2000.00152.x

Barisoni, L., W. Kriz, P. Mundel and V. D’Agati, 1999. The dysregulated podocyte phenotype: A novel concept in the pathogenesis of collapsing idiopathic focal segmental glomerulosclerosis and HIVassociated nephropathy. J. Am. Soc. Nephrol., 10: 51-61. PMID: 9890309

Bruggeman, L.A., M.D. Ross, N. Tanji, J.A. Winston and P.E. Klotman et al., 2000. Renal epithelium is a previously unrecognized site of HIV-1 infection. J. Am. Soc. Nephrol., 11: 2079-2087. PMID: 11053484

Bruggeman, L.A., S. Dikman, C. Meng, C. Meng and S.E. Quaggin et al., 1997. Nephropathy in human immunodeficiency virus-1 transgenic mice is due to renal transgene expression. J. Clin. Invest., 100: 8492. DOI: $10.1172 /$ JCI119525

Burns, G.C., R. Matute, D. Onyema, I. Davis and I. Toth, 1994. Response to inhibition of angiotensinconverting enzyme in human immunodeficiency virus-associated nephropathy: A case report. Am. J. Kidney Dis., 23: 441-443. PMID: 8128948

Burns, G.C., S.K. Paul, I.R. Toth and S.L. Sivak, 1997. Effect of angiotensin-converting enzyme inhibition in HIV-associated nephropathy. J. Am. Soc. Nephrol., 8: 1140-1146. PMID: 9219164

Chan, K.T., N. Papeta, J. Martino, Z. Zheng and P.E. Klotman et al., 2009. Accelerated development of collapsing glomerulopathy in mice congenic for the HIVAN1 locusAccelerated nephropathy in HIVAN1 congenic mice. Kidney Int., 75: 366-372. DOI: 10.1038/ki.2008.625

Chen, P., B.K. Chen, A. Mosoian, M.E. Klotman and P.E. Klotman et al., 2011. Virological synapses allow HIV-1 uptake and gene expression in renal tubular epithelial cells. J. Am. Soc. Nephrol., 22: 496-507. DOI: 10.1681/ASN.2010040379

D'Agati, V.D., A.B. Fogo, J.A. Bruijn and J.C. Jennette, 2004. Pathologic classification of focal segmental glomerulosclerosis: A working proposal. Am. J. Kidney Dis., 43: 368-382. DOI: 10.1053/j.ajkd.2003.10.024
DeWan, A.T., D.K. Arnett, L.D. Atwood, C.E. Lewis and S.C. Hunt et al., 2001. A genome scan for renal function among hypertensives: The HyperGEN study. Am. J. Hum. Genet., 68: 136-144. DOI: $10.1086 / 316927$

Doublier, S., C. Zennaro, T. Spatola, E. Lupia and A. Bottelli et al., 2007. HIV-1 Tat reduces nephrin in human podocytes: A potential mechanism for enhanced glomerular permeability in HIVassociated nephropathy. AIDS, 21: 423-432. DOI: 10.1097/QAD.0b013e328012c522

Eitner, F., Y. Cui, K.L. Hudkins, P.L. Kimmel and C.E. Alpers et al., 2000. Chemokine receptor CCR5 and CXCR4 expression in HIV-associated kidney disease. J. Am. Soc. Nephrol., 11: 856-867. PMID: 10770963

Eustace, J.A., E. Nuermberger, M. Choi, P.J.J. Scheel and R. Moore et al., 2000. Cohort study of the treatment of severe HIV-associated nephropathy with corticosteroids. Kidney Int., 58: 1253-1260. PMID: 10972688

Freedman, B.I., P.J. Hicks, M.A. Bostrom, M.E. Cunningham and C.A. Winkler et al., 2009. Polymorphisms in the non-muscle myosin heavy chain 9 gene (MYH9) are strongly associated with end-stage renal disease historically attributed to hypertension in African Americans. Kidney Int., 75: 736-745. DOI: 10.1038/ki.2008.701

Gharavi, A.G., T. Ahmad, R.D. Wong, R. Hooshyar and J. Vaughn et al., 2004. Mapping a locus for susceptibility to HIV-1-associated nephropathy to mouse chromosome 3. Proc. Natl. Acad. Sci., 101: 2488-2493. DOI: 10.1073/pnas.0308649100

Hatsukari, I., P. Singh, N. Hitosugi, S. Teichberg and W. Chaung et al., 2007. DEC-205-mediated internalization of HIV-1 results in the establishment of silent infection in renal tubular cells. J. Am. Soc. Nephrol., $\quad$ 18: 780-787. DOI: 10.1681/ASN.2006121307

He, J.C., M. Husain, M. Sunamoto, P.E. Klotman and R. Iyengar et al., 2004. Nef stimulates proliferation of glomerular podocytes through activation of Srcdependent Stat3 and MAPK1,2 pathways. J. Clin. Invest., 114: 643-651. DOI: 10.1172/JCI21004

He, J.C., T.C. Lu, M. Fleet, P.E. Klotman and R. Iyengar et al., 2007. Retinoic Acid Inhibits HIV-1-Induced Podocyte Proliferation through the cAMP Pathway. J. Am. Soc. Nephrol., 18: 93-102. DOI: 10.1681/ASN.2006070727

Husain, M., G.L. Gusella, M.E. Klotman, E.J. Schwartz and M.D. Ross et al., 2002. HIV-1 nef induces proliferation and anchorage-independent growth in podocytes. J. Am. Soc. Nephrol., 13: 1806-1815. PMID: 12089376 
Husain, M., V.D. D’Agati, J.C. He, M.E. Klotman and P.E. Klotman et al., 2005. HIV-1 Nef induces dedifferentiation of podocytes in vivo: A characteristic feature of HIVAN. AIDS, 19: 19751980. PMID: 16260903

Imperatore, G., R.L. Hanson, D.J. Pettitt, S. Kobes and P.H. Bennett et al., 1998. Sib-pair linkage analysis for susceptibility genes for microvascular complications among Pima Indians with type 2 diabetes. Pima Diabetes Genes Group. Diabetes, 47: 821-830. DOI: 10.2337/diabetes.47.5.821

Kao, W.H., M.J. Klag, L.A. Meoni, L.A. Meon and J. Coresh et al., 2008. MYH9 is associated with nondiabetic end-stage renal disease in African Americans. Nat. Genet., 40: 1185-1192. DOI: 10.1038/ng.232

Kapasi, A.A., G. Patel, N. Franki and P.C. Singhal, 2002. HIV-1 gp120-induced tubular epithelial cell apoptosis is mediated through p38-MAPK phosphorylation. Mol. Med., 8: 676-685.

Kaufman, L., G. Yang, K. Hayashi, P.E. Klotman and M.E. Klotman et al., 2007. The homophilic adhesion molecule sidekick-1 contributes to augmented podocyte aggregation in HIV-associated nephropathy. FASEB J., 21: 1367-1375. DOI: 10.1096/fj.06-7191 com

Kaufman, L., K. Hayashi, M.J. Ross and P.E. Klotman, 2004. Sidekick-1 is upregulated in glomeruli in HIV-associated nephropathy. J. Am. Soc. Nephrol., 15: 1721-1730.

DOI: 10.1097/01.ASN.0000128975.2895

Kaufman, L., U. Potla, S. Coleman, V.D. D'Agati and H. Kurihara et al., 2010. Up-regulation of the homophilic adhesion molecule sidekick-1 in podocytes contributes to glomerulosclerosis. J. Biol. Chem., 285: 25677-25685. DOI: 10.1074/jbc.M110.133959

Kimmel, P.L., G.J. Mishkin and W.O. Umana, 1996. Captopril and renal survival in patients with human immunodeficiency virus nephropathy. Am. J. Kidney Dis., 28: 202-208. PMID: 8768914

Kopp, J.B., M.W. Smith, G.W. Nelson, B.I. Freedman and D.W. Bowden et al., 2008. MYH9 is a majoreffect risk gene for focal segmental glomerulosclerosis. Nat. Genet., 40: 1175-1184. DOI: $10.1038 /$ ng.226

Kumar, D., S. Konkimalla, A. Yadav, P.N. Chander and P.C. Singhal et al., 2010. HIV-associated nephropathy: Role of mammalian target of rapamycin pathway. Am. J. Pathol., 177: 813-821. DOI: 10.2353/ajpath.2010.100131
Lescure, F.X., C. Flateau, J. Pacanowski, P.M. Girard and E. Rondeau et al., 2012. HIV-associated kidney glomerular diseases: Changes with time and HAART. Nephrol. Dial. Trans., 27: 2349-2355. DOI: $10.1093 / \mathrm{ndt} / \mathrm{gfr} 676$

Lucas, G.M., J.A. Eustace, S. Sozio, E.K. Mentari and K.A. Appiah et al., 2004. Highly active antiretroviral therapy and the incidence of HIV-1associated nephropathy: A 12-year cohort study. AIDS, 18: 541-546. PMID: 15090808

Marras, D., L.A. Bruggeman, F. Gao, N. Tanji and B.H. Hahn et al., 2002. Replication and compartmentalization of HIV-1 in kidney epithelium of patients with HIV-associated nephropathy. Nat. Med., 8: 522-526. DOI: 10.1038/nm0502-522

Medapalli, R.K., J.C. He and P.E. Klotman 2011. HIVassociated nephropathy: Pathogenesis. Curr. Opin. Nephrol. Hypertens., 20: 306-311. DOI: 10.1097/MNH.0b013e328345359a

Mikulak, J. and P.C. Singhal, 2010. HIV-1 entry into human podocytes is mediated through lipid rafts. Kidney Int., 77: 72-73. DOI: 10.1038/ki.2009.366

Mikulak, J., S. Teichberg, S. Arora, D. Salhan and P.C. Singhal et al., 2010. DC-specific ICAM-3-grabbing nonintegrin mediates internalization of HIV-1 into human podocytes. Am. J. Physiol. Renal. Physiol., 299: F664-673. DOI: 10.1152/ajprenal.00629.2009

Mocroft, A., R. Brettle, O. Kirk, Z. Fox and J.D. Lundgren et al., 2002. Changes in the cause of death among HIV positive subjects across Europe: Results from the EuroSIDA study. AIDS, 16: 1663-1671. DOI: 10.1097/00002030-200208160-00012

Moczulski, D.K., J.J. Rogus, A. Antonellis, J.H. Warram and A.S. Krolewski et al., 1998. Major susceptibility locus for nephropathy in type 1 diabetes on chromosome 3q: Results of novel discordant sib-pair analysis. Diabetes, 47: 1164-1169. DOI: 10.2337/diabetes.47.7.1164

PAGAA, 2003. Guidelines for the use of antiretroviral agents in HIV-1-infected adults and adolescents. Department of Health and Human Services.

Papeta, N., K.T. Chan, S. Prakash, R.P. Lifton and H. Zhao et al., 2009. Susceptibility loci for murine HIV-associated nephropathy encode trans-regulators of podocyte gene expression. J. Clin. Invest., 119: 1178-1188. DOI: 10.1172/JCI37131

Pardo, V., M. Aldana, R.M. Colton, L. Moskowitz and G.T. Hensley et al., 1984. Glomerular lesions in the acquired immunodeficiency syndrome. Ann. Int. Med., 101: 429-434. PMID: 6476632 
Post, F.A., L.J. Campbell, L. Hamzah, P.J. Easterbrook and J.O. Connolly et al., 2008. Predictors of renal outcome in HIV-associated nephropathy. Clin. Infect. Dis., 46: 1282-1289. DOI: 10.1086/529385

Rao, T.K., E.J. Filippone, A.D. Nicastri, D. Anthony and M.D. Nicastri et al., 1984. Associated focal and segmental glomerulosclerosis in the acquired immunodeficiency syndrome. N. Eng. J. Med., 310: 669-673. DOI: 10.1056/NEJM198403153101101

Ray, P.E., 2012. HIV-associated nephropathy: A diagnosis in evolution. Nephrol. Dial. Transplant, 27: 3969-3972. DOI: 10.1093/ndt/gfs114

Ray, P.E., X.H. Liu, D. Henry, L. Dye and T.E. Schuztbank, et al., 1998. Infection of human primary renal epithelial cells with HIV-1 from children with HIV-associated nephropathy. Kidney Int., 53: $1217-1229$. DOI: $10.1046 / \mathrm{j} .1523-$ 1755.1998.00900.x

Rosenstiel, P., A. Gharavi, V. D’Agati and P. Klotman, 2009a. Transgenic and infectious animal models of HIV-associated nephropathy. J. Am. Soc. Nephrol., 20: 2296-2304. DOI: 10.1681/ASN.2008121230

Rosenstiel, P.E., J. Chan, A. Snyder, P.E. Klotman and M.E. Klotman et al., 2009b. HIV-1 Vpr activates the DNA damage response in renal tubule epithelial cells. AIDS, 23: 2054-2056. DOI: 10.1097/QAD.0b013e32833088a0

Rosenstiel, P.E., T. Gruosso, A.M. Letourneau, A.M. Letourneau and V. Planelles et al., 2008. HIV-1 Vpr inhibits cytokinesis in human proximal tubule cells. Kidney Int., 74: 1049-1058. DOI: 10.1038/ki.2008.303

Ross, M.J., C. Fan, M.D. Ross, P.E. Klotman and M.E. Klotman et al., 2006b. HIV-1 infection initiates an inflammatory cascade in human renal tubular epithelial cells. J. Acquir. Immune. Defic. Syndr., 42:

$$
1-11 \text {. }
$$

DOI:

10.1097/01.qai.0000218353.60099.4f

Ross, M.J., M.S. Wosnitzer, M.D. Ross, P.E. Klotman and M.E. Klotman et al., 2006a. Role of ubiquitinlike protein FAT10 in epithelial apoptosis in renal disease. J. Am. Soc. Nephrol., 17: 996-1004. DOI: 10.1681/ASN.2005070692

Ross, M.J., S. Martinka, V.D. D’Agati and L.A. Bruggeman, 2005. NF- $\kappa$ B regulates Fas-mediated apoptosis in HIV-associated nephropathy. J. Am. Soc. Nephrol., 16: 2403-2411. DOI: 10.1681/ASN.2004121101

Schwartz, E.J., A. Cara, H. Snoeck, P. Mundel and P.E. Klotman et al., 2001. Human immunodeficiency virus-1 induces loss of contact inhibition in podocytes. J. Am. Soc. Nephrol., 12: 1677-1684. PMID: 11461940
Schwartz, E.J., L.A. Szczech, M.J. Ross, M.E. Klotman and J.A. Winston et al., 2005. Highly active antiretroviral therapy and the epidemic of HIV+ end-stage renal disease. J. Am. Soc. Nephrol., 16: 2412-20. DOI: 10.1681/ASN.2005040340

Smith, M.C., J.L. Austen, J.T. Carey, R.A. Salata and R.C. Kalayjian et al., 1996. Prednisone improves renal function and proteinuria in human immunodeficiency virus-associated nephropathy. Am. J. Med., 101: 41-48. DOI: 10.1016/S00029343(96)00065-4

Smith, M.C., R. Pawar, J.T. Carey, A. Menon and R.C. Kalayjian et al., 1994. Effect of corticosteroid therapy on human immunodeficiency virusassociated nephropathy. Am. J. Med., 97: 145-151. DOI: 10.1016/0002-9343(94)90024-8

Snyder, A., Z.C. Alsauskas, J.S. Leventhal, M.J. Ross and P.E. Klotman et al., 2010. HIV-1 viral protein R induces ERK and caspase-8-dependent apoptosis in renal tubular epithelial cells. AIDS, 24: 1107-1119. DOI: 10.1097/QAD.0b013e328337b0ab

Tanji, N., M.D. Ross, K. Tanji, P.E. Klotman and V.D. D'Agati et al., 2006. Detection and localization of HIV-1 DNA in renal tissues by in situ polymerase chain reaction. Histol. Histopathol., 21: 393-401. PMID: 16437385

Thompson, M.A., J.A. Aberg, J.F. Hoy, D.M. Jacobsen and P.A. Volberding et al., 2012. Antiretroviral treatment of adult HIV infection: 2012 recommendations of the International Antiviral Society-USA panel. JAMA, 308: 387-402. DOI: 10.1001/jama.2012.7961

Trullas, J.C., F. Cofan, M. Tuset, J.M. Campistol and J.M. Miro et al., 2011. Renal transplantation in HIVinfected patients: 2010 update. Kidney Int., 79: 825842. DOI: $10.1038 / \mathrm{ki} .2010 .545$

USRDS, 2010. Annual data report: Atlas of chronic kidney disease and end-stage renal disease in the United States. National Institutes of Health.

Vashistha, H., M. Husain, D. Kumar, S. Arora and P.C. Singhal et al., 2008. HIV-1 expression induces tubular cell G2/M arrest and apoptosis. Renal Failure, 30: 655-664. DOI: 10.1080/08860220802134672

Watterson, M.K., R.K. Detwiler and P.J. Bolin, 1997. Clinical response to prolonged corticosteroids in a patient with human immunodeficiency virusassociated nephropathy. Am. J. Kidney Dis., 29: 624-626. DOI: 10.1016/S0272-6386(97)90348-6 
Wearne, N., C.R. Swanepoel, A. Boulle, M.S. Duffield and B.L. Rayner, 2012. The spectrum of renal histologies seen in HIV with outcomes, prognostic indicators and clinical correlations. Nephrol. Dial. Transplant, 27: 4109-4118. DOI: 10.1093/ndt/gfr702

Wei, A., G.C. Burns, B.A. Williams, N.B. Mohammed and P. Visintainer et al., 2003. Long-term renal survival in HIV-associated nephropathy with angiotensin-converting enzyme inhibition. Kidney Int., 64: 1462-1471. DOI: 10.1046/j.15231755.2003.00230.x

Wyatt, C.M., K. Meliambro and P.E. Klotman, 2012. Recent progress in HIV-associated nephropathy. Annu. Rev. Med., 63: 147-159. DOI: 10.1146/annurev-med-041610-134224

Wyatt, C.M., P.E. Klotman and V.D. D'Agati, 2008. HIV-associated nephropathy: Clinical presentation, pathology and epidemiology in the era of antiretroviral therapy. Semin. Nephrol., 28: 513-522. DOI: $10.1016 /$ j.semnephrol.2008.08.005
Yahaya, I., A.O. Uthman and M.M. Uthman, 2013. Interventions for HIV-associated nephropathy. Cochrane Database Syst. Rev., 1: 7183-7183. DOI: 10.1002/14651858.CD007183.pub3

Zhong, J., Y. Zuo, J. Ma, I. Ichikawae and T. Matsusaka et al., 2005. Expression of HIV-1 genes in podocytes alone can lead to the full spectrum of HIV-1-associated nephropathy. Kidney Int., 68: 1048-1060. DOI:

10.1111/j.15231755.2005.00497.x

Zuo, Y., T. Matsusaka, J. Zhong, A.B. Fogo and P. Jolicoeur et al., 2006. HIV-1 genes vpr and nef synergistically damage podocytes, leading to glomerulosclerosis. J. Am. Soc. Nephrol., 17: 28322843. DOI: 10.1681/ASN.2005080878 